\title{
CLÁUdIO OU A DIALÉTICA DO BUCOLISMO
}

\author{
Leandro Sarmatz
}

RESUMO: This is a reading on Cláudio Manuel da Costa's sonnets which aims at detecting tensions between culture and rusticity, tradition and lack of history. It intends to unfold the idea of a "Brazilian bucolic" - retake of the historical patrimony to trace the limits of the New World tradition - the interior of Cláudio Manoel da Costa's poetry.

PALAVRAS-CHAVE: Cláudio Manoel da Costa, bucolismo, tradição clássica.

Ainda não se pode responder com certeza a muitas das perguntas suscitadas pelo exame da literatura do Brasil no século XVIII. Gerações de estudiosos perderam o sono tentando descobrir o pronome correto para designar a produção literária em terras brasileiras no período colonial: tratava-se de "nossa" literatura ou da literatura "deles"?

Um caminho é começar por onde a pergunta se faz mais sonora, que é justamente o "caso" de Cláudio Manuel da Costa. Mas esse caminho na verdade é o primeiro passo para se resvalar num pântano de idéias-feitas, enterrando-se até a cabeça em referências histórico-literárias que já estão cristalizadas no domínio da crítica. É só falar em Cláudio Manuel da Costa, que qualquer estudante universitário de literatura brasileira já tem uma verdadeira fortuna crítica na ponta da língua: é o poeta da "majestosa calma", cujos versos se destacavam pela "sobriedade do caráter" numa arte que, como a do italiano Metastasio, guarda "o endereço predominantemente bucólico de seu estro". (As aspas pertencem, respectivamente, a Antonio Candido, Alfredo Bosi e Sérgio Buarque de Holanda, alguns dos críticos mais lidos e ensinados em nossas universidades nas últimas décadas.)

O que devemos fazer é ler tais diagnósticos criticamente, tentando perceber aqui e ali o quanto há de exagero e mesmo de conveniência na leitura do poeta inconfidente. Habituou-se a ver em Cláudio - cuja obra pertence, por justiça e valor, ao universo das escolhas temáticas e estilísticas da poesia de feição neoclássica, apega- 
da ao bucolismo e aos ideais da Arcádia - uma figura de transição. No caso, a passagem do mundo de inspiração greco-romana, embora ainda impregnado de alguns ecos conceptistas, para os primeiros vagidos do Romantismo. Como não é o objetivo deste trabalho provar que o poeta é ou não é uma figura de transição, mas o de tentar captar certas ambivalências nos usos que ele faz do bucolismo e de sua venerável tradição, podemos prestar reverência a alguns de nossos mais estimados mestres - e tomá-lo então como personalidade que não raro escorrega nos degraus da escada construída pela história das letras.

Que a arte de Cláudio Manuel da Costa caracteriza-se pela sobriedade, disso ninguém mais parece ter dúvida. $\mathrm{O}$ poeta, adestrado no bom senso horaciano, apresenta uma dicção que não peca por excesso de qualquer natureza, mesmo quando, pleno de horror, seu olhar captura um daqueles penhascos que tanto aparecem em seus sonetos. Parece ter assimilado com eficácia a lição de Boileau, para quem dublado em português -

"Não há monstro odioso, nem serpente,

Que não possa agradar bem imitado;

Com pincel delicado docemente

O objeto mais horrível faz-se amado (...)

(BOILEAU, s/d, Canto III, p. 61)

No "Prólogo" de suas Obras (1768), Cláudio confessa-se "propenso mais para o sublime". Não começaremos uma queda-de-braço com o poeta, porém devemos admitir que, às vezes, a pessoa menos indicada para uma crítica equilibrada é justamente o próprio autor. O "sublime", no caso, é a estética estridente do barroco. Falamos há pouco em "bucolismo clássico", e, anteriormente, em "Arcádia". É hora de colocarmos Cláudio no banco de reservas - e de convocarmos alguns conceitos precisos. De acordo com Ernst Robert Curtius (1996), os pastores viviam na região conhecida como Arcádia, cuidavam de gado bovino (daí "bucólica"). O siracusano Teócrito (II a. C.) foi quem iniciou a tradição, porém, segundo Curtius, o responsável pela fixação de temas e imagens foi mesmo Virgílio (que já não habitava a terra de sonhos dourados de Teócrito). A poesia pastoral entrou na corrente sangüínea da literatura ocidental quando a Arcádia já era uma projeção poética, melhor dizendo, uma construção ficcional. Daí a impressão de que as Bucólicas de Virgílio parecem mais elaboradas do que os idílios de Teócrito; já não se tratava de captar a realidade, mas de transfigurá-la, transformando-a em matéria mesclada à imaginação.

Wolfgang Iser, estudando o gênero bucólico e suas relações com a ficcionalidade literária, diz que o bucólico, desde seus primórdios, tematiza o fingimento mas anseia o real: A paisagem ideal é uma representação da natureza que oculta o caráter de representação: estar em lugar de um outro (ISER, 1996, p. 50). Daí que exigir verossimilhança de tal arte é pedir que ela se aproxime perigosamente das fronteiras do embuste. A Arcádia encerra projeções, e como projeção ela deve ser tomada - é o "mundo edulcorado" de que fala Raymond Williams em O campo e a cidade. O poeta adquire modos de pastor para construir um universo mais coerente dentro de sua obra pretensamente "bucólica". 
De tal ficcionalização surgiram muitas noções desafinadas. Um exemplo: quando a voga bucólica retornou a partir da Renascença, ela foi incorporada principalmente pelos filhos mais diletos da terra - os cortesãos. Como todo processo cultural é seleção de uns, refutação e "esquecimento" de outros, tirou-se a conclusão de que os pastores da longínqua Arcádia eram aristocratas. Se os modos desses aristocratas e escritores da Renascença em diante eram a mímica afetada do que se julgava ser o bucólico legítimo, certas nuances do espírito denunciavam as mudanças que seu tempo anunciava. A principal delas é que, com freqüência, o olhar não mais era o do singelo camponês, mas do cientista e do naturalista.

Também começavam a atentar para o valor econômico da terra. Em Paisagem e memória, livro no qual estuda a paisagem como construção cultural do Ocidente, o historiador Simon Schama percebe o caráter exploratório que se dá à natureza quando escreve: A idílica paisagem arcádica (...) parecer ser mais uma bela mentira contada pelas aristocracias proprietárias (...) a fim de disfarçar as conseqüencias ecológicas de sua cobiça (SCHAMA, 1996, p. 23).

Foi no século XVIII, no entanto, que a Arcádia reapareceu com toda sua força. Para tanto, contribuiu a glorificação da simplicidade. Era uma espécie de resposta aos excessos cometidos pela rica ornamentação barroca. Tal ideal passou para a contemplação da natureza, agora vista com olhar mais ameno, para o comedimento de meios expressivos, e, enfim, para uma estética de aparência mais "natural". O declínio da metáfora durante esse período de passagem para o Arcadismo é uma reação a não raro intoxicante metáfora conceptista.

Em página clássica de Formação da literatura brasileira, Antonio Candido aventa uma interpretação desse ressurgimento do bucólico em pleno Século das Luzes. Diz que a sobrevivência do tema talvez esteja ligada ao desenvolvimento da cultura urbana; o campo então seria mais ou menos como é hoje o sítio nos arredores das grandes cidades: um refúgio idílico, capaz de devolver ao homem certas potências há muito deixadas para trás. Uma espécie de Idade de Ouro em miniatura, evocando uma vida que é muito mais invenção e memória do que realidade.

O problema dessa naturalidade forçada é que ela está a um passo da banalização. Como a Idade de Ouro pode ser invocada como apanágio universal para as dores reais ou não, sua contrapartida é uma simplificação de modos de vida há muito desaparecidos e de sentimentos que, por causa dessa "visão mais chã" (como escreve Antonio Candido), aparecem com menos profundidade. ${ }^{1}$

\footnotetext{
${ }^{1}$ Resguardadas as devidas e necessárias proporções, podemos vincular esse apelo a uma hipotética Idade de Ouro ao surgimento, a partir da segunda metade de nosso século, das estéticas gauchescas e sertanejas no âmbito da cultura popular brasileira. Em ambas, a migração em massa de camponeses para as grandes cidades gerou um sentimento de "paraíso perdido", evocado em vestuário, danças típicas, canções e formação de grupos folclóricos, que reproduzem a estrutura social da zona rural — inclusive em suas relações de poder, como a figura do "patrão" no CTG. Recentemente, no contexto internacional, o famigerado terrorista "Unabomber", com sua recusa brutal ao mundo da tecnologia e o apelo utópico por um ambiente natural, sem máquinas e motores, é a face mais trágica (e patética) desse quadro.
} 
(Aliás, quando se fala em "simplicidade" neste período histórico, o termo deve vir acompanhado por todas as aspas possíveis. No arcadismo setecentista, a herança popular que havia desde Teócrito foi solenemente desprezada pelos intelectuais. Era crime de "lesa-estilo" tentar macaquear a fala popular, raiz da poesia bucólica. O campesino serviu apenas como alegoria e veículo para a refinada cultura aristocrática deplorar a miçanga barroca.)

Antigas formas de vida podem voltar, mas nunca reaparecem intocadas. O tempo e os homens costumam modificá-las, de acordo com os ares de sua época. Essa sobrevida adquire sempre o aspecto fantasmagórico dos cacoetes e das modas. Não foi diferente com o retorno do bucólico no século XVIII. Se, em sua origem virgiliana, o mundo campestre já era uma projeção literária, uma ficcionalização, nada mais natural que ele também o fosse em sua reencarnação setecentista. Tratava-se de ajustálo aos ditames do bom gosto vigente - equilíbrio e decoro neoclássicos, certo espírito galante e nobre, educação e leveza, jogos campestres, amores ligeiros, simplicidade no escrever. Uma estética do meio-termo. Nada de muito campestre que sugerisse a rudeza de uma vida selvagem, nem de muito requintado que pudesse soar a barroquismo. Diz o nosso Boileau em versão lusa:

"No estilo pastoril o bom Poeta

Desperte, e lisonjêe com doçura;

Não com fúria pomposa, e indiscreta

Siga do oculto idioma a frase escura (...)

Difficultoso entre esse dous extremos

He o caminho de hum perfeito Idílio:

Para o achar sigamos, e imitamos

O estilo de Theocrito, e Virgílio" (...)

(Op. cit., Canto II, pp. 44 e 46)

Em Cláudio Manuel da Costa os ideais de uma arte construída no equilíbrio e na leitura dos clássicos colidem com a contemplação do meio agreste de seu torrão natal. Quase estrangeiro em solo nativo, com a cabeça e os olhos voltados para o mundo clássico, Cláudio parece não encontrar uma Arcádia que se equipare àquela dos poetas europeus:

"Onde estou? Este sítio desconheço;

Quem fez tão diferente aquele prado?

Tudo outra natureza tem tomado.

E em contemplá-lo, tímido, esmoreço.

Uma fonte aqui houve; eu não me esqueço

De estar a ela um dia reclinado;

Ali em vale um monte está mudado:

Quanto pode dos anos o progresso!

Árvores aqui vi tão florescentes, Que faziam perpétua a primavera: 
Nem troncos vejo agora decadentes.

Eu me engano: a região esta não era;

Mas que venho a estranhar, se estão presentes

Meus males, com que tudo degenera!"

(COSTA, 1996, soneto VII, p.53-4)

O soneto que acabamos de ler parece enunciar, descontado seu tom de indagação e de espanto, aquela famosa afirmação de Sérgio Buarque de Holanda em Raízes do Brasil sobre o caráter brasileiro, de que somos ainda hoje uns desterrados em nossa terra. À imagem do locus amoenus da lírica bucólica, Cláudio sobrepõe uma outra, mental, construída em sua cabeça através da leitura dos clássicos: Uma fonte aqui houve; eu não me esqueço / De estar a ela um dia reclinado (...). A fonte, como sabemos, é um dos três elementos clássicos do locus amoenus. As outras são: uma árvore e uma campina. Mas o poeta mineiro é o primeiro a perceber que, mesmo tentando visualizar a paisagem clássica : (...) a região esta não era.

E nem podia ser mesmo. Não apenas porque a Arcádia, inclusive em solo europeu, era uma paragem distante no tempo e no espaço, mas também porque o Brasil talvez agastasse o poeta e despertasse em seu espírito a saudade pelas terras d'além-mar. No "Prólogo" de suas Obras, Cláudio escreveu, querendo parecer isento de qualquer sentimento negativo: A desconsolação de não poder substabelecer aqui as delícias do Tejo, do Lima e do Mondego me fez entorpecer o engenho dentro do meu berço, mas nada bastou para deixar de confessar a seu respeito a maior paixão.

Cláudio parecia ter noção de que a Arcádia já surgiu como uma "paisagem espiritual" para utilizarmos a rica expressão de Bruno Snell (Apud: Iser, op. cit., p.47). Ainda no famoso "Prólogo", escreveu: Conheço que só entre as delícias do Pindo se podem nutrir aqueles espíritos, que desde o berço se destinaram a tratar as Musas (...). As Musas clássicas realmente ajudaram a fecundar o poeta, que, pelo fato de não encontrar na paisagem nativa a inspiração de seus colegas europeus (pois as terras daqui ainda não haviam sido tocadas pela história), e também por ter consciência de que tudo era invenção cultural, lamenta:

"Musas, canoras Musas, este canto

Vós me inspirastes, vós meu tenro alento

Erguestes brandamente àquele assento,

Que tanto, ó Musas, prezo, adoro tanto.

Se em campo não pisados algum dia

Entre a Ninfa, o Pastor, a ovelha, o touro,

Efeitos são da vossa melodia;

Que muito, ó Musas, pois que em fausto agouro

Cresçam do pátrio rio à margem fria

A imarcescível hera, o verde louro!"

(Op. cit., soneto C, p. 96)

Em tom velado de reproche, José Aderaldo Castello comenta que a arte de 
Cláudio caracteriza-se pela disciplina de uma paisagem artificialmente concebida (1972, p. 137). A melhor definição acerca das ambivalências do poeta é da lavra de Antonio Candido, que diz coexistir no poeta o bairrista mineiro com o afetado coimbrão (1994, p.84). É perfeita, mas também serviria para rotular praticamente todo o descendente de portugueses que pôde realizar estudos na Europa no século XVIII - aqueles poucos filhos do nascente patriciado. Cláudio Manuel, porém, parece aqui e ali mostrar algumas tensões que o habilitam a representante (e talvez único praticante) de uma "bucólica brasileira", se tal título não for um delírio deste leitor.

A tal "bucólica brasileira" é uma retomada de temas e imagens da bucólica tradicional com uma visada hesitante desse mesmo patrimônio, tudo com a função de "aprofundar" a paisagem do jovem país, fornecendo-lhe amplitude e uma História até então praticamente nulos. Escreve Cláudio:

"Memórias do presente, e do passado

Fazem guerra cruel dentro do meu peito,

E bem que ao sofrimento ando já feito,

Mais do que nunca desperta hoje cuidado.

Que diferente, que diverso estado

É este, em que somente o triste efeito

Da pena, a qual meu mal me tem sujeito

Me acompanha entre aflito e magoado!

Tristes lembranças! e que em vão componho

A memória da vossa sombra escura!

Que néscio em vós a ponderar me ponho!

Ide-vos; que em tão mísera loucura

Todo o passado bem tenho por sonho;

Só é certa a presente desventura."

(Op. cit., soneto L, p. 73)

É bem possível que o inconfidente Cláudio Manuel da Costa tenha encontrado na problematização do patrimônio da Arcádia um motivo a mais na sua insurreição colonial. Sérgio Buarque de Holanda detecta que, na recusa à "linguagem alambicada" da Metrópole, há uma "imposição patriótica". Pois o poeta escreve:

"Se sou pobre Pastor, se não governo

Reino, nações, províncias, mundo e gentes;

Se em frio, calma e chuvas inclementes

Passo o verão, outono, estio, inverno;

Nem por isso trocara o abrigo terno

Desta choça, em que vivo, co'as enchentes

Dessa grande fortuna: assaz presentes

Tenho as paixões desse tormento eterno. 


\begin{abstract}
Adorar traições, amar o engano, Ouvir dos lastimosos o gemido, Passar aflito o dia, o mês, o ano,

Seja embora prazer; que a meu ouvido Soa melhor a voz do desengano, Que da torpe lisonja o infame ruído."

(Op. cit., soneto V, p. 53)
\end{abstract}

Simon Schama diz que a paisagem é uma espécie de texto em que as gerações escrevem suas obsessões recorrentes (op. cit., p. 23). No caso do poeta mineiro, sua paisagem é texto antes de ser paisagem, porém aspirando captar vivamente algo da natureza real. A saída parecer ter sido aquela abundância de imagens de pedra em sua obra: "altas serras", "penhas", "rochedos". O ex-aluno erudito de Coimbra, cônscio do que melhor se fazia em termos de literatura, parecia ter em vista, com suas alusões bucólicas retiradas da lírica européia mescladas à representação de formas duras e descendentes (porque sempre as serras e penhascos aparecem visto de cima para baixo), dar uma grandeza e uma violência quase épicas a uma paisagem praticamente casta em termos de representação — porém há muito explorada em todas as suas potencialidades econômicas. Porque havia, sim, já uma "longa" história: desde 1696, pelo menos, a exploração de metais preciosos se desenvolvia em Minas Gerais, configurando verdadeira "corrida do ouro", ajudando a alçar Lisboa ao segundo posto de capital econômica européia, perdendo apenas para Londres.

(Se resolvermos seguir aquele argumento de Schama a respeito da paisagem como um texto no qual as gerações escrevem suas obsessões, veremos que tal ligação entre o meio e os temas do país atravessa o nervo de nossa literatura até hoje. Poucas gerações depois de Cláudio, e em chave diversa, José de Alencar iria escrever as "obsessões" de seu tempo — a autonomia do caráter brasileiro entre a maior delas em uma série de romances que capturam tipos de várias regiões de nosso território, dando-lhes conformação assumidamente nacional. Depois, teríamos a relação — ou o divórcio absoluto - entre civilização litorânea e interior abandonado do país em Euclides da Cunha, Monteiro Lobato, Simões Lopes Neto, nos romancistas de 30, e, em nível de realização artística de primeira grandeza e riqueza verbal inaudita, em Grande sertão: veredas. A partir da década de 60, narradores como João Antônio e Rubem Fonseca elegeram a grande cidade, não por acaso o Rio de Janeiro, como palco para um vigoroso debate sobre as mazelas da frenética urbanização do país ocorrida a partir da segunda metade do século.)

Tendo em vista que Cláudio Manuel da Costa conseguiu injetar em uma poesia de contornos plácidos o desassossego e a tensão entre velho e novo, tradição e falta de história, cultura e rusticidade, a conclusão a que se pode chegar é que, nos primórdios da literatura brasileira, o poeta mineiro teve a sensibilidade para captar determinadas questões que animam nossa vida intelectual e política até hoje. Alguém poderá objetar, dizendo que antes dele houve aquela mistura de deboche e reverência praticada por Gregório de Matos. Mas Gregório - centralíssimo - era irreverente 
em poesia moldada para tal, e religioso quando o momento era de falar na sacristia. Cláudio não. Ele trouxe o espanto de nossa novidade no mapa-múndi para dentro de uma arte consagrada à evocação de um universo que há muito deixara de existir (ou mesmo jamais existira, se aceitarmos a proposta de Iser). Dando contorno àquilo que chamamos aqui de "bucólica brasileira" - a referência à bucólica clássica com uma tomada de posição, eminentemente crítica, diante de nossa absoluta falta de história —, e impregnando a paisagem de seus sonetos com uma aspereza que serve para comentar ambos, texto e paisagem, Cláudio embaralhou os clichês e iludiu quem esperava dele um Arcádia transplantada. Só por ter ajudado a desenvolver esse impasse que é, afinal de contas, um dos grandes impasses da cultura brasileira, o poeta já mereceria um lugar de honra em nossos estudos.

\section{BIBLIOGRAFIA}

BOILEAU. L'art poétique/Arte poética. Lisboa, s/d.

CANDIDO, Antonio. Formação da literatura brasileira - momentos decisivos. 5 ed. São Paulo/Belo Horizonte, EDUSP/Itatiaia, 1975.

CASTELLO, José Aderaldo. Manifestações literárias do período colonial. 3 ed. São Paulo, Cultrix, 1981.

COSTA, Cláudio Manuel da. A poesia dos inconfidentes - Obra completa. Rio de Janeiro, Nova Aguilar, 1996.

CURTIUS, Ernst Robert. Literatura européia e Idade Média latina. São Paulo, Hucitec, 1996.

ISER, Wolfgang. A bucólica da Renascença como paradigma da ficcionalidade literária. In: O fictício e o imaginário. Rio de Janeiro, EDUERJ, 1996.

SCHAMA, Simon. Paisagem e memória. São Paulo, Companhia das Letras, 1996. 